\title{
Serum anti-Mullerian hormone predicts ovarian response in (Macaca fascicularis) monkeys
}

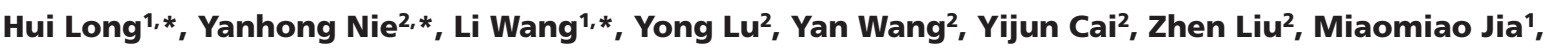 \\ Qifeng Lyu' ${ }^{1}$, Yanping Kuang ${ }^{1}$ and Qiang Sun ${ }^{2}$ \\ 'Department of Assisted Reproduction, Shanghai Ninth People's Hospital, Shanghai Jiaotong University School of Medicine, Shanghai, China \\ 2Institute of Neuroscience, State Key Laboratory of Neuroscience, Key Laboratory of Primate Neurobiology, CAS Center for Excellence in Brain Science \\ and Intelligence Technology, Shanghai Institutes for Biological Sciences, Chinese Academy of Sciences, Shanghai, China
}

Correspondence should be addressed to Q Sun or Y Kuang or Q Lyu: qsun@ion.ac.cn or Kuangyanp@126.com or lyuqifeng@126.com

*(H Long, Y Nie and L Wang contributed equally to this work)

\begin{abstract}
$\mathrm{AMH}$ as a promising predictor of ovarian response has been studied extensively in women undergoing assisted reproductive technology treatment, but little is known about its prediction value in monkeys undergoing ovarian stimulation. In the current study, a total of 380 cynomolgus monkeys ranging from 5 to 12 years received 699 ovarian stimulation cycles. Serum samples were collected for AMH measure with enzyme-linked immunosorbent assay. It was found that serum $\mathrm{AMH}$ levels were positive correlated with the number of retrieved oocytes $(P<0.01)$ in the first, second and third stimulation cycles. In the first cycles, area under the curve $\left(\mathrm{ROC}_{\mathrm{AUC}}\right)$ of $\mathrm{AMH}$ is 0.688 for low response and 0.612 for high response respectively, indicating the significant prediction values $(P=0.000$ and $P=0.005)$. The optimal AMH cutoff value was $9.68 \mathrm{ng} / \mathrm{mL}$ for low ovarian response and $15.88 \mathrm{ng} / \mathrm{mL}$ for high ovarian response prediction. In the second stimulation cycles, the significance of $\mathrm{ROC}_{\mathrm{AUC}}$ of $\mathrm{AMH}$ for high response rather than the low response was observed $(P=0.001$ and $P=0.468)$. The optimal AMH cutoff value for high ovarian response was $15.61 \mathrm{ng} / \mathrm{mL}$. In the third stimulation cycles, $A M H$ lost the prediction value with no significant $\mathrm{ROC}_{\mathrm{AUC}}$. Our data demonstrated that $A M H$, not age, is a cycle-dependent predictor for ovarian response in form of oocyte yields, which would promote the application of $\mathrm{AMH}$ in assisted reproductive treatment (ART) of female cynomolgus monkeys. AMH evaluation would optimize candidate selection for ART and individualize the ovarian stimulation strategies, and consequentially improve the efficiency in monkeys.
\end{abstract}

\author{
Key Words \\ - anti-Mullerian hormone \\ - prediction \\ - number of retrieved \\ oocytes \\ - ovarian response \\ - cynomolgus monkeys
}

\section{Introduction}

Due to the similarities to human beings in reproductive physiology and endocrinology, nonhuman primates have been served as an ideal model for human reproductive biology, gynecology and other diseases (1, 2, 3), especially the cynomolgus monkeys with no seasonal breeding. To date, assisted reproductive technology (ART) was routinely applied in nonhuman primates to produce in vitro-derived embryos and offspring, which largely advanced the research of somatic cell nuclear transfer and the embryo stem cell establishment $(4,5)$. These achievements were dependent on an amount of oocytes retrieval in ovarian stimulation. However, ovarian stimulation regimen in nonhuman primates has not been set up as well as human beings, and the high cost of medicine used also limited the availability of large number of oocytes. Regarding ovarian stimulation,
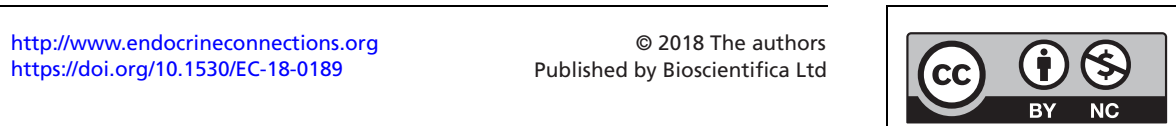

This work is licensed under a Creative Commons Attribution-NonCommercial 4.0 International License. 
the efficiency of ART in nonhuman primates has the great potential to improve.

In controlled ovarian stimulations, the characteristics, such as age, menstrual cycle length and results from previous in vitro fertilization (IVF) cycles are generally considered for ovarian stimulation strategies. Apart from these factors, several ovarian markers, such as antral follicle count (AFC) (6), estradiol concentration (7), basal FSH (8), inhibin and AMH (9), have been used to estimate the ovarian response to tailor ovarian stimulation protocols in human beings (10). As for the advancement in clinical practices to obtain satisfactory results, it is valuable to evaluate ovarian response to gonadotropin before ART in monkeys.

$\mathrm{AMH}$ is a homodimeric glycoprotein and secreted from preantral and small antral follicles as recruited from the follicle pool in females $(11,12)$. Thus, it is considered as the reliable marker of ovarian reserve, reflecting both the quantity and the quality of the resting primordial ovarian follicle pool (13). Both woman and female monkeys have the similar AMH expression pattern, with a peak during the fertility period and becoming undetectable around the menopause $(14,15,16)$. Further, AMH exhibited lower inter- and intra-cycle variability $(17,18)$, which make it a better predictor of ovarian response in IVF cycles than both AFC and FSH level (10). To date, AMH is widely used in prediction of ovarian response and clinical outcomes in humans (19) and other species, such as cow (20), sheep (21) and goats (22). However, the role of AMH in prediction of ovarian response in monkeys has not been uncovered.

Considering the great importance of nonhuman primate models and promising applications of $\mathrm{AMH}$ in ART, its predictability in monkeys deserved to be assessed. The present study aimed to explore the correlation between serum AMH levels and the number of retrieved oocytes after ovarian stimulation and to determine the role of $\mathrm{AMH}$ as a predictor for the ovarian response in monkeys undergoing IVF cycles, which will help to individualize and optimize the ovarian stimulation regimen in nonhuman primates.

\section{Materials and methods}

\section{Animals}

A total of 380 cynomolgus monkeys and 699 cycles were included. Animals were maintained in social groups and housed in outdoor compounds with attached indoor

$$
\begin{aligned}
& \text { http://www.endocrineconnections.org } \\
& \text { https://doi.org/10.1530/EC-18-0189 }
\end{aligned}
$$

() 2018 The authors Published by Bioscientifica Ltd quarters. The use and care of animals complied with the guideline of the Biomedical Research Ethics Committee at the Shanghai Institutes for Biological Science (CAS) under the approval application entitled 'Reproductive physiology of cynomolgus monkeys and establishment of transgenic monkeys' (\#ER-SIBS-221106P). They had menstrual cycles between 22 and 36 days and had no hormone exposure during the last 2 months before testing AMH levels. Our data showed that ovarian stimulation had no effect on AMH levels. No significant differences were observed in serum AMH levels among the groups receiving different times of ovarian stimulation cycles at given age (Supplementary Fig. 1, see section on supplementary data given at the end of this article, $P>0.5)$.

\section{Ovarian stimulation treatment and oocyte retrieval}

Ovarian stimulation was conducted as the routine protocol. The initial dose of 15-30 IU FSH (Recombinant Human Follitropin for Injection; Merck Serono SA Aubonne Branch. Co.) was administrated twice a day from menstrual cycle day 3. Ovarian sizes of monkeys were monitored by B-scan ultrasonography from menstrual cycle day 10 onward. 1000-1500 IU HCG (chorionic gonadotropin human; SIGMA-ALDRICH, Co.) were used to trigger ovulation when more than ten follicles were larger than $3 \mathrm{~mm}$ in diameter. $33-38 \mathrm{~h}$ after hCG administration, monkeys were anesthetized with tiletamine hydrochloride (4 to $6 \mathrm{mg} / \mathrm{kg}$, Zoletil 50; Virbac S.A.) intramuscularly, and cumulus-oocyte complexes were collected by laparoscopic follicular aspiration.

\section{AMH assay}

Blood was withdrawn via an intravenous catheter and transferred into tubes for centrifugation. All serum was isolated from blood samples and was measured using an ELISA kit according to the manufacturer's instructions (AMH ELISA, AL-105, Ansh Labs, USA) $(15,16)$. The assay was validated by demonstrating parallelism between the standard curve and the serially diluted monkey serum samples. High and low AMH calibrators were run in all assays and the values were within the assay's acceptable ranges. The range of the AMH standards used in the assay was from 0.09 to $16.4 \mathrm{ng} / \mathrm{mL}$. The intra-assay coefficients of variation were less than $8 \%$, and inter-assay coefficient was less than $12 \%$. 


\section{Statistical analysis}

One-way ANOVA and $t$ tests were used to compare the differences in three and two groups respectively. Pearson correlation coefficients were performed to examine the associations among serum AMH, age and oocyte outcome in different stimulation cycles. Receiver operator curves (ROC) were used to analyze the sensitivity and specificity of $\mathrm{AMH}$ at different levels in predicting low ovarian response (number of retrieved oocytes $\leq 14$ ) and high ovarian response (number of retrieved oocytes $\geq 51$ ) respectively (about $10 \%$ of the cohort was defined as the low or high responders in our study). High and normal response data were used for cutoff values analysis for high response, and low and normal response data were used for cutoff values analysis for low response. Significance was assigned at $P<0.05$. All analyses were performed using SPSS software package (24.0) or SigmaPlot (10.0)

\section{Results}

\section{Characteristics and oocyte retrieval}

A total of 380 female cynomolgus monkeys were included in this study. The statistical characteristics of age, AMH and oocytes retrieved from 699 ovarian stimulation cycles were categorized according to the number of cycle times and summarized in Table 1 . Both age and serum AMH levels were similar among the three different stimulation cycles ( $P=0.089, P=0.706$, respectively, Table 1$)$. There was no significance in the number of retrieved and metaphase II (MII) oocytes between the first and second stimulation cycles and also between the second and third cycles (Table 1). Compared with the first cycles, the significant decline in the number of retrieved oocytes rather than metaphase II was observed in the third cycle $(33.6 \pm 20.5$ vs $27.6 \pm 18.9, P<0.01$, Table 1 ).

\section{Correlations of age, AMH and oocyte outcomes}

To determine the effect of ovarian stimulation on AMH level, samples from the monkeys who received repeated ovarian stimulation were analyzed. There was no difference observed in AMH levels among different age groups from 5 to 12 years. In the same age section, no significant differences were observed in AMH levels among the groups undergoing different times of ovarian stimulation (Supplementary Fig. 1), indicating that AMH was relatively stable across several stimulation cycles. Then, Pearson correlation analysis was conducted to examine the relationships of $\mathrm{AMH}$ and age in the total participants. Our data revealed that AMH levels were positively correlated with age $(r=0.151, P=0.002$, Table 2$)$.

Univariate analysis showed that both the number of retrieved oocytes and MII oocytes had no relationships with age $(P>0.05$, Table 2$)$ in all stimulation cycles, but showed a positive correlation with $\mathrm{AMH}$ level in the first and second stimulation cycles $(P<0.05$, Table 2$)$. In the third cycle, although there also was a positive correlation between $\mathrm{AMH}$ levels and the number of retrieved oocytes ( $r=0.316, P=0.009$ ), the number of MII oocytes showed no significant correlation with AMH $(r=0.211$, $P=0.083$, Table 2).

\section{AMH for prediction of low and high ovarian response}

ROCs were plotted to depict the predictive potential of $\mathrm{AMH}$ in low and high ovarian response in stimulation cycles. The area under the curve of ROC $\left(\mathrm{ROC}_{\mathrm{AUC}}\right)$ exhibited the ability of AMH levels for predicting the high and low response in the first cycles, and the high response in the second cycles $(P<0.05)$, while no significant ROCAUC was observed in the third cycles (Table 3 ). The sensitivity and specificity of AMH at different levels were analyzed in predicting value. The cutoff values were determined as well.

Table 1 Characteristics of age, AMH and oocyte retrieval in different cycles.

\begin{tabular}{|c|c|c|c|c|}
\hline & First cycle $(n=380)$ & Second cycle $(n=251)$ & Third cycle $(n=68)$ & $P$ value \\
\hline Age (years) & $8.2 \pm 2.5$ & $8.4 \pm 2.4$ & $8.9 \pm 2.6$ & 0.089 \\
\hline $\mathrm{AMH}(\mathrm{ng} / \mathrm{mL})$ & $15.3 \pm 5.0$ & $15.5 \pm 4.8$ & $15.8 \pm 4.4$ & 0.706 \\
\hline Retrieved oocytes & $33.6 \pm 20.5$ & $31.3 \pm 12.3$ & $27.6 \pm 18.9^{\# \#}$ & $0.048 *$ \\
\hline MII oocytes & $13.2 \pm 10.9$ & $12.3 \pm 10.6$ & $10.4 \pm 10.0$ & 0.112 \\
\hline
\end{tabular}

Values are presented as mean \pm S.D. $P$ value by one-way ANOVA. ${ }^{*} P<0.05$. Compared with the second cycle, $\# P<0.001$.

$\mathrm{AMH}$, anti-Mullerian hormone; MII, metaphase II.

$$
\begin{array}{lr}
\text { http://www.endocrineconnections.org } & \text { () } 2018 \text { The authors } \\
\text { https://doi.org/10.1530/EC-18-0189 } & \text { Published by Bioscientifica Ltd }
\end{array}
$$


Table 2 Correlation analyses among age, AMH, the number of retrieved oocytes and metaphase II oocytes in different ovarian stimulation cycles.

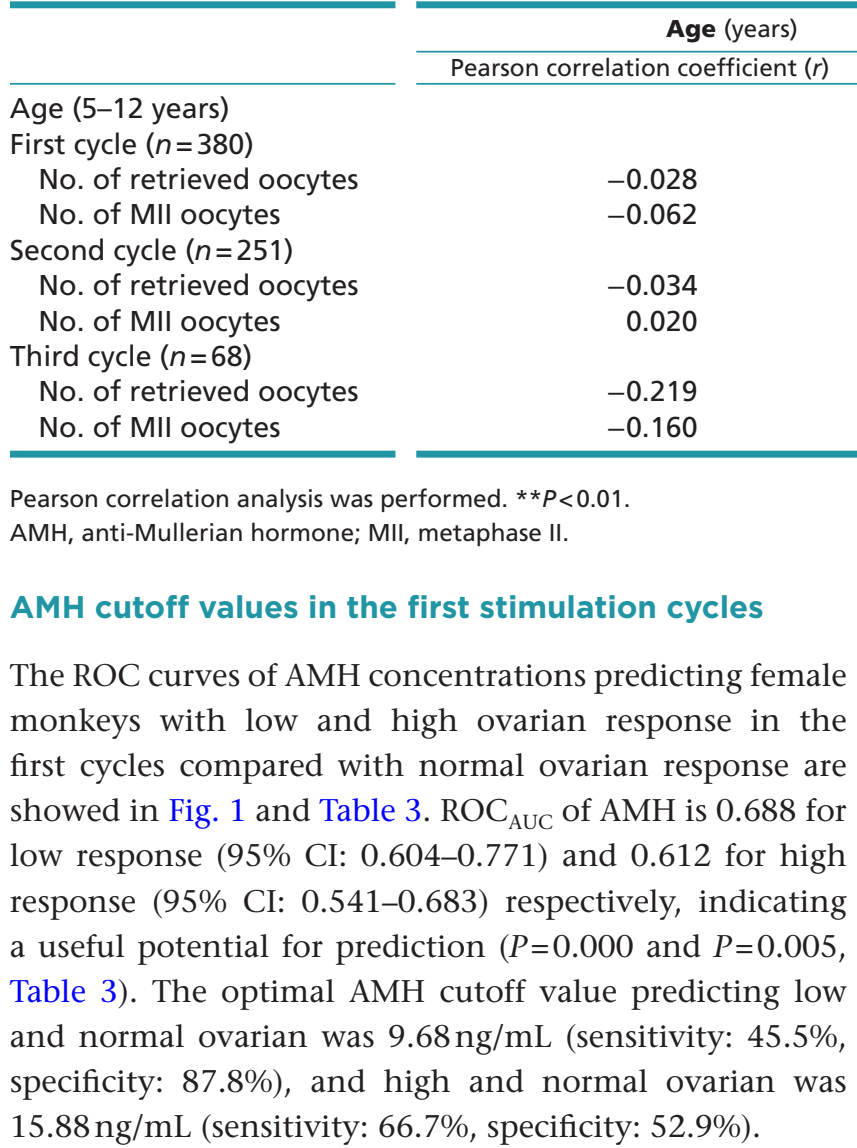

\section{AMH cutoff values in the second stimulation cycles}

The ROC curves of AMH concentrations predicting female monkeys with low and high ovarian response in the second cycles compared with normal ovarian response are showed in Fig. 1 and Table 3. The $\mathrm{ROC}_{\mathrm{AUC}}$ of $\mathrm{AMH}$ is 0.535 for low response (95\% CI: $0.435-0.636$ ) and 0.673 for high response (95\% CI: $0.584-0.784)$ respectively. The significance of $\mathrm{ROC}_{\mathrm{AUC}}$ of $\mathrm{AMH}$ for high response rather than the low response was observed in the second cycles ( $P=0.001$, and $P=0.468$, respectively, Table 3$)$, indicating the potential predictive utility. The optimal $\mathrm{AMH}$ cutoff value for high ovarian response was $15.61 \mathrm{ng} / \mathrm{mL}$ (sensitivity: $82.4 \%$, specificity: $54.3 \%$ ) compared with the normal response.

\section{Discussion}

This study represents the first published report of AMH prediction of ovarian response in monkeys undergoing ovarian hyperstimulation. Our data demonstrated a positive association between serum AMH and the number of retrieved oocytes in 699 stimulation cycles of cynomolgus monkeys ranged from 5 to 12 years $(P<0.01)$. Allowing for chronologic age, AMH can be regarded as a significant predictor of poor and high ovarian response in the first stimulation cycles and high ovarian response in the second cycles $(P<0.001)$, but lost the prediction role of low ovarian response in the second and both responses in the third stimulation cycles from ROC analysis. It is possible due to the decrease in the number of retrieved oocytes after repeated cycles, but AMH is still maintained stably between the cycles shown in our data.

Regarding the ovarian response in repeated cycles, there are disagreements in the results reported. Some studies showed that the ovarian responses were similar in consecutive cycles (23), while others reported that ovarian

Table 3 Potential of AMH to predict low and high response in different ovarian stimulation cycles.

\begin{tabular}{|c|c|c|c|}
\hline \multirow[b]{2}{*}{ Cycle } & \multicolumn{3}{|c|}{ Low response } \\
\hline & $\mathrm{ROC}_{\mathrm{AUC}}$ & $95 \% \mathrm{Cl}$ & $P$ value \\
\hline First & 0.688 & $(0.604,0.771)$ & $0.000 * * *$ \\
\hline Second & 0.535 & $(0.435,0.636)$ & 0.468 \\
\hline Third & 0.642 & $(0.499,0.784)$ & 0.077 \\
\hline
\end{tabular}

\begin{tabular}{|c|c|c|}
\hline \multicolumn{3}{|c|}{ High response } \\
\hline $\mathrm{ROC}_{\mathrm{AUC}}$ & $95 \% \mathrm{Cl}$ & $P$ value \\
\hline 0.612 & $(0.541,0.683)$ & $0.005 * *$ \\
\hline 0.673 & $(0.584,0.761)$ & 0.001 ** \\
\hline 0.618 & $(0.418,0.818)$ & 0.102 \\
\hline
\end{tabular}

$P$ value means significance of $\mathrm{ROC}_{\mathrm{AUC}}$ compared with $0.5 . * * P<0.01$. $* * * P<0.001$

$\mathrm{AMH}$, anti-Mullerian hormone

$$
\begin{array}{lr}
\text { http://www.endocrineconnections.org } & \text { ○ } 2018 \text { The authors } \\
\text { https://doi.org/10.1530/EC-18-0189 } & \text { Published by Bioscientifica Ltd }
\end{array}
$$


A

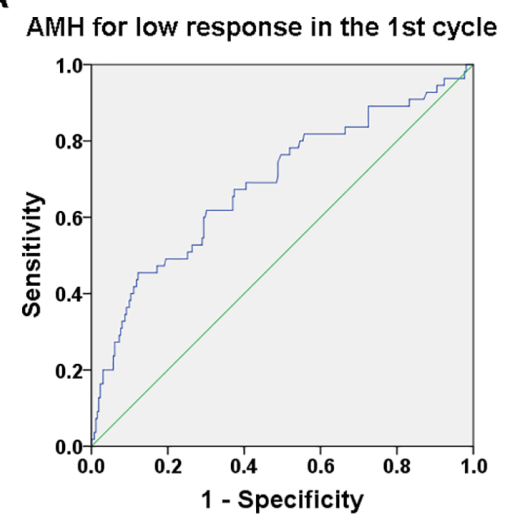

C

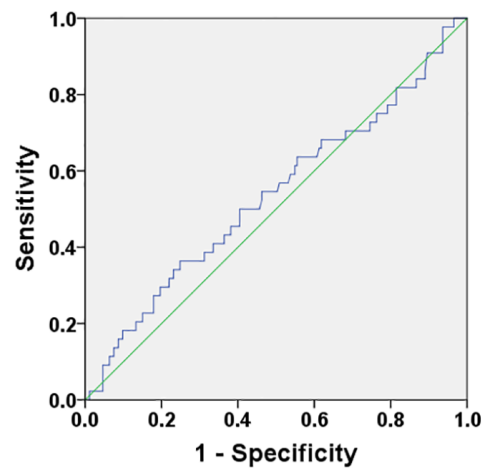

B

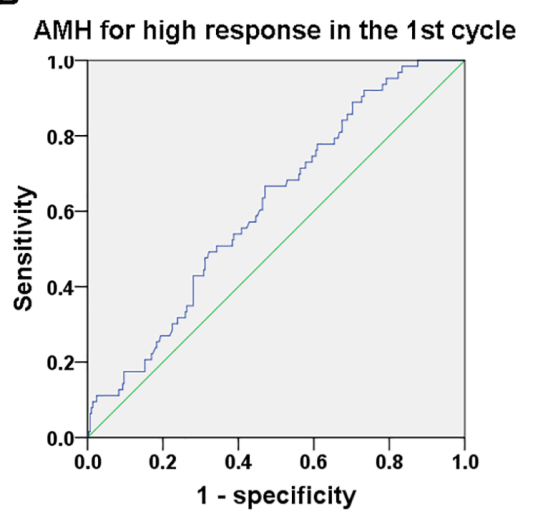

D

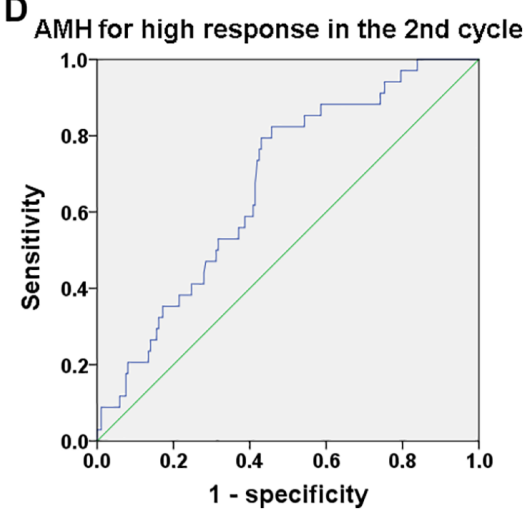

\section{Figure 1}

AMH receiver operator characteristic $(\mathrm{ROC})$ curves for low and high ovarian response predictions in the first and second cycle respectively. stimulations led to the decrease of the retrieved oocytes in rhesus monkey (24). Our data showed that, there was a decline in the number of retrieved oocytes with the growing stimulation accounts, which consequently led to the different predictability of AMH in the first, second and third stimulation cycles. The decrease of oocyte yields was also observed in rhesus monkeys undergoing repeated ovarian stimulation (24). It is proved that repeat ovarian stimulations only altered the expression of proteins in ovaries, but not ovarian structure and function (25), which might be the reason why AMH level was maintained stably as indicated in our data.

Age is one of the traditional factors used for measuring the ovarian reservation in humans $(10,26)$. With age, ovarian reservation falls to a critical level, finally leading to menopause. As well, nonhuman primates have the similar characteristics (15). In the cohort of cynomolgus monkeys during the primary fertility period, age showed the positive correlation with AMH levels, but had no significant correlation with the number of retrieved oocytes observed in our data. Even though age can partially reflect ovarian aging related to the decline of the quantity and quality of the follicle pool, it is not an appropriate predictor in ovarian response in monkeys that was also proved in humans (10). In addition, the comparison of predictive value between $\mathrm{AMH}$ and other ovarian markers, such as AFC and FSH, has not been performed in the current study due to lack of strict hormone monitor as in humans during ovarian stimulation, which limited the acknowledgement of other ovarian response predictors in monkeys.

Using cutoffs of AMH to select appropriate candidates for ovarian stimulation will improve the efficiency of ART in monkeys. Definitely, the cutoff values with high sensitivity and specificity can only be considered as screening markers. In the first stimulation cycles, the AMH cutoff value was $9.68 \mathrm{ng} / \mathrm{mL}$ for predicting low ovarian response with a specificity of $87.8 \%$ and a sensitivity of $45.5 \%$. It is clear that $\mathrm{AMH}$ had a modest sensitivity for poor response, and thus, it would include the candidates with poor response for ovarian stimulation. The higher cutoff values than $9.68 \mathrm{ng} / \mathrm{mL}$ should be considered for exclusion of false negative ones in practice. On the other hand, the individual adjustment of the dose of gonadotropins in poor responders is also effective in increasing the success rate of ovarian stimulation. In regard to high response, the cutoff values of $\mathrm{AMH}$ were similar in the first and second stimulation cycles,

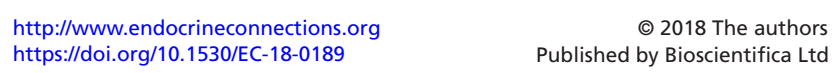


while had different sensitivity and specificity. Considering the potential risk of ovarian hyperstimulation syndrome (OHSS) in primates, the high sensitivity was preferable.

It is well known that AMH levels, as a marker of severity of ovarian dysfunction, are elevated up to twoto three-fold in PCOS patients (27). PCOS is the most common cause of infertility, and the occurrence reached $6-10 \%$ in women of reproductive age (28). The PCOS like status is believed to be existing in an unselected cohort of cynomolgus monkeys during fertility period. Thus, high AMH level, especially much higher than the cutoff value for high ovarian response should be ill advised for ovarian stimulation, due to the potential bad quality of retrieved oocytes and risk of OHSS.

Taken together, serum AMH can be used as a cycledependent predictor of ovarian response in cynomolgus monkeys treated with ovarian stimulations. It will provide the reference criteria for candidate selection for ART in monkeys. The optimal AMH cutoff values gained in this study will promote the individualization and optimization of ovarian stimulation regimen and therefore improve the efficiency of ART in cynomolgus monkeys.

\section{Supplementary data}

This is linked to the online version of the paper at https://doi.org/10.1530/ ECC-18-0189.

\section{Declaration of interest}

The authors declare that there is no conflict of interest that could be perceived as prejudicing the impartiality of the research reported.

\section{Funding}

This work was supported by grants from Shanghai Municipal Government Bureau of Science and Technology project (16JC1420202 to Q S), Natural Science Foundation of China (81571397, 81771533 to Y K and 81571486) to $\mathrm{Q} \mathrm{L}$.

\section{Author contribution statement}

Hui Long, Yanhong Nie, Li Wang and Miaomiao Jia participated in experiment execution and manuscript drafting; Yong Lu and Yan Wang participated in experiment execution and data analysis; Yijun Cai and Zhen Liu participated in data analysis and critical discussion; Qifeng Lyu, Yanping Kuang and Qiang Sun participated in study design and critical discussion.

\section{References}

1 Terasawa E. Control of luteinizing hormone-releasing hormone pulse generation in nonhuman primates. Cellular and Molecular Neurobiology 199515 141-164. (https://doi.org/10.1007/BF02069563)

2 Appt SE. Usefulness of the monkey model to investigate the role soy in postmenopausal women's health. ILAR Journal 200445 200-211. (https://doi.org/10.1093/ilar.45.2.200)
3 Freeman EW, Sammel MD, Lin H, Boorman DW \& Gracia CR. Contribution of the rate of change of antimullerian hormone in estimating time to menopause for late reproductive-age women. Fertility and Sterility 201298 1254-1259.e1-2. (https://doi. $\operatorname{org} / 10.1016 /$ j.fertnstert.2012.07.1139)

4 Byrne JA, Pedersen DA, Clepper LL, Nelson M, Sanger WG, Gokhale S, Wolf DP \& Mitalipov SM. Producing primate embryonic stem cells by somatic cell nuclear transfer. Nature $2007 \mathbf{4 5 0} 497-502$. (https://doi.org/10.1038/nature06357)

5 Liu Z, Cai Y, Wang Y, Nie Y, Zhang C, Xu Y, Zhang X, Lu Y, Wang Z, Poo $\mathrm{M}$, et al. Cloning of macaque monkeys by somatic cell nuclear transfer. Cell 2018172 881-887.e7. (https://doi.org/10.1016/j. cell.2018.01.020)

6 Broer SL, Dolleman M, Opmeer BC, Fauser BC, Mol BW \& Broekmans FJ. AMH and AFC as predictors of excessive response in controlled ovarian hyperstimulation: a meta-analysis. Human Reproduction Update 201117 46-54. (https://doi.org/10.1093/ humupd/dmq034)

7 Hendriks DJ, Klinkert ER, Bancsi LF, Looman CW, Habbema JD, te Velde ER \& Broekmans FJ. Use of stimulated serum estradiol measurements for the prediction of hyperresponse to ovarian stimulation in in vitro fertilization (IVF). Journal of Assisted Reproduction and Genetics 200421 65-72. (https://doi.org/10.1023/ B:JARG.0000027016.65749.ad)

8 Fourati S, Merdassi G, Khrouf M, Elloumi H, Fadhlaoui A, Brahmi I, Hammami N, Ben Slima S, Ben Meftah M, Zhioua F, et al. [Basal fsh level is only predictive of the quantitative aspect of the ovarian response]. La Tunisie médicale 201290 524-529.

9 Knauff EA, Eijkemans MJ, Lambalk CB, ten Kate-Booij MJ, Hoek A, Beerendonk CC, Laven JS, Goverde AJ, Broekmans FJ, Themmen AP, et al. Anti-Mullerian hormone, inhibin B, and antral follicle count in young women with ovarian failure. Journal of Clinical Endocrinology and Metabolism 200994 786-792. (https://doi.org/10.1210/jc.2008-1818)

10 Jamil Z, Fatima SS, Ahmed K \& Malik R. Anti-mullerian hormone: above and beyond conventional ovarian reserve markers. Disease Markers 20162016 5246217. (https://doi.org/10.1155/2016/5246217)

11 Jeppesen JV, Anderson RA, Kelsey TW, Christiansen SL, Kristensen SG, Jayaprakasan K, Raine-Fenning N, Campbell BK \& Yding Andersen $\mathrm{C}$. Which follicles make the most anti-Mullerian hormone in humans? Evidence for an abrupt decline in $\mathrm{AMH}$ production at the time of follicle selection. Molecular Human Reproduction 201319 519-527. (https://doi.org/10.1093/molehr/ gat024)

12 McGee EA \& Hsueh AJ. Initial and cyclic recruitment of ovarian follicles. Endocrine Reviews 200021 200-214. (https://doi. org/10.1210/edrv.21.2.0394)

13 Domingues TS, Rocha AM \& Serafini PC. Tests for ovarian reserve: reliability and utility. Current Opinion in Obstetrics and Gynecology 201022 271-276. (https://doi.org/10.1097/GCO.0b013e32833b4f5c)

14 Lie Fong S, Visser JA, Welt CK, de Rijke YB, Eijkemans MJ, Broekmans FJ, Roes EM, Peters WH, Hokken-Koelega AC, Fauser BC, et al. Serum anti-mullerian hormone levels in healthy females: a nomogram ranging from infancy to adulthood. Journal of Clinical Endocrinology and Metabolism 201297 4650-4655. (https://doi. org/10.1210/jc.2012-1440)

15 Atkins HM, Willson CJ, Silverstein M, Jorgensen M, Floyd E, Kaplan JR \& Appt SE. Characterization of ovarian aging and reproductive senescence in vervet monkeys (Chlorocebus aethiops sabaeus). Comparative Medicine 201464 55-62.

16 Appt SE, Clarkson TB, Chen H, Adams MR, Christian PJ, Hoyer PB, Wilson ME \& Kaplan JR. Serum antimullerian hormone predicts ovarian reserve in a monkey model. Menopause 200916 597-601. (https://doi.org/10.1097/gme.0b013e3181906fb6)

17 Hehenkamp WJ, Looman CW, Themmen AP, de Jong FH, Te Velde ER $\&$ Broekmans FJ. Anti-Mullerian hormone levels in the spontaneous menstrual cycle do not show substantial fluctuation. Journal of

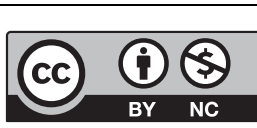


Clinical Endocrinology and Metabolism 200691 4057-4063. (https:// doi.org/10.1210/jc.2006-0331)

18 La Marca A, Stabile G, Artenisio AC \& Volpe A. Serum antiMullerian hormone throughout the human menstrual cycle. Human Reproduction 200621 3103-3107. (https://doi.org/10.1093/humrep/ del291)

19 Broer SL, Broekmans FJ, Laven JS \& Fauser BC. Anti-Mullerian hormone: ovarian reserve testing and its potential clinical implications. Human Reproduction Update 201420 688-701. (https:// doi.org/10.1093/humupd/dmu020)

20 Souza AH, Carvalho PD, Rozner AE, Vieira LM, Hackbart KS, Bender RW, Dresch AR, Verstegen JP, Shaver RD \& Wiltbank MC. Relationship between circulating anti-Mullerian hormone (AMH) and superovulatory response of high-producing dairy cows. Journal of Dairy Science 201598 169-178. (https://doi.org/10.3168/jds.20148182)

21 Lahoz B, Alabart JL, Cocero MJ, Monniaux D, Echegoyen E, Sanchez P \& Folch J. Anti-Mullerian hormone concentration in sheep and its dependence of age and independence of BMP15 genotype: an endocrine predictor to select the best donors for embryo biotechnologies. Theriogenology 201481 347-357. (https:// doi.org/10.1016/j.theriogenology.2013.09.033)

22 Monniaux D, Baril G, Laine AL, Jarrier P, Poulin N, Cognie J \& Fabre S. Anti-Mullerian hormone as a predictive endocrine marker for embryo production in the goat. Reproduction 2011142 845-854. (https://doi.org/10.1530/REP-11-0211)
23 VandeVoort CA \& Tarantal AF. Recombinant human gonadotropins for macaque superovulation: repeated stimulations and post-treatment pregnancies. Journal of Medical Primatology 200130 304-307. (https://doi.org/10.1034/j.16000684.2001.300603.X)

24 Yang S, Shen Y, Niu Y, Hildebrandt TB, Jewgenow K, Goeritz F, He X, Zhou Q \& Ji W. Effects of rhFSH regimen and time interval on ovarian responses to repeated stimulation cycles in rhesus monkeys during a physiologic breeding season. Theriogenology 200870 108-114. (https://doi.org/10.1016/j. theriogenology.2008.03.012)

25 Dong G, Guo Y, Cao H, Zhou T, Zhou Z, Sha J, Guo X \& Zhu H. Long-term effects of repeated superovulation on ovarian structure and function in rhesus monkeys. Fertility and Sterility 20141021452 1457 e1451. (https://doi.org/10.1016/j.fertnstert.2014.07.739)

26 Vidal JD. The impact of age on the female reproductive system. Toxicologic Pathology 201745 206-215. (https://doi. org/10.1177/0192623316673754)

27 Bungum L, Franssohn F, Bungum M, Humaidan P \& Giwercman A. The circadian variation in Anti-Mullerian hormone in patients with polycystic ovary syndrome differs significantly from normally ovulating women. PLOS ONE 20138 e68223. (https://doi. org/10.1371/journal.pone.0068223)

28 Teede HJ \& Norman R. Polycystic ovarian syndrome: insights into the enigma that is PCOS today. Endocrine 200630 1-2. (https://doi. org/10.1385/ENDO:30:1:1)

Received in final form 16 July 2018

Accepted 3 August 2018

Accepted Preprint published online 8 August 2018 http://www.endocrineconnections.org https://doi.org/10.1530/EC-18-0189

(c) 2018 The authors Published by Bioscientifica Ltd
This work is licensed under a Creative Commons Attribution-NonCommercial 4.0 International License. 